segment of the pelvic floor, allow the anterior vaginal wall to bag, and following it the uterine body and appendages. It is upon the woman whose daily labour is hard and exacting that this condition presses the most heavily. Prolapse or procidentia means to her crippled usefulness, and in many instances total inability to follow the occupation which has brought her bread. When the anal sphincteric fibres have been torn incompletely, incontinence of flatus and liquid freces are produced, with liability to frequently recurring attacks of diarrhcea. With complete rupture there supervenes a condition so intolerable that its sufferers are ready to loathe even their very existence. The treatment of these cases resolves itself into the preventive and the curative. The first and most important presupposes an intelligent appreciation of the mechanism of parturition, and carrying its lessons into practice. The correction of malpresentation and of misdirection of the propulsive force, preventing precipitate labour by direct backward pressure upon the presenting part, the judicious use of chloroform, injunctions to cease voluntary efforts, avoidance of ergot and supplementing in other cases the muscular contractions by the careful use of the forceps, briefly summarise the main indications. The Dublin plan of taking off the blades of the forceps when the vulvar outlet is reached is worthy of adoption. When laceration is impending and unavoidable, its extent may be limited by notching either side of the raphe. The accident having happened, unless extremely trifling and tegumentary, its immediate repair is demanded and towards the general adoption of this practice when needed no parturient woman should be left without a visual examination of the vulvar outlet being made. Stunned by the passage of the child, the parts are less sensitive than later, and the bringing together of the torn surfaces is a matter not difficult of accomplishment. The relaxed state of the parts also favours apposition. Even as late as a week after confinement I have obtained perfect union in a deep laceration. When the time for the primary operation has passed, it is well to wait till after the cessation of lactation; the procedure is then more or less troublesome according to the extent of tissue involved and the general health of the patient. When the laceration is incomplete vivification of the cicatrised surfaces, accurate apposition, and careful after-treatment make this operation one of the most successful in surgery ; but if the recto-vaginal septum is more or less destroyed, its renewal requires considerable skill. In two recent cases of extensive rents of the septum I have obtained excellent results by making two vaginal and two rectal flaps (as suggested, I believe, by Mr. Hulke), getting between them a good perineal body. For the flaps carbolised silk is better than catgut, unless chromicised catgut is used, because of its speedy solution; and for the deep perineal sutures silver wire is preferable, simply twisted or fastened by perforated shot. Vaginal injections are usually practised after the operation; but it seems to me better to pack the vagina with an absorbent aseptic material like iodoform cotton-wool, thus getting all the advantage to be derived from rest to the parts-pressure and dryness. This need not often be changed. A self-retaining catheter, either a Skene-Goodman or a Holt with attached tubing, keeps the patient free from urinous dribbling. The accumulation of flatus may interfere with healthy union, and to obviate this the occasional use of a rectal tube is indicated. The period at which the bowels should be relieved is a moot point, and an important one. If too soon, it must, I think, interfere with the reparative process, unless the utmost care is taken ; and if too long delayed, the passage of scybalæe may rupture the young tissues. When the latter are suspected, means should be taken to break them up; and in addition to a saline purgative an enema of oil should be administered.

Nottingham.

Convalescent ATD. - On the 24th inst., a meeting was held at the Mansion House in support of the plan of convalescent aid adopted by the Charity Organisation Society. Lord Carnarvon, who occupied the chair, stated that the scheme had been in existence now for over twelve months, and up to the present had worked well. A resolution to the effect that convalescent aid has a most important bearing upon the health of the people, was carried unanimously. As a proof of the importance of such work, we may mention that the Me r spolitan Convalescent Institution has since its forma. tion relieved nearly 100,000 persons.
A CASE OF

SYPHILITIC PARAPLEGIA, WITH REMARKS.

BY WILLIAM S. PORTER, M.D.,

PHYSICIAN TO THE SHEFFIELD PUBLIC HOSPITAL AND DISPENSARY.

W. B-C, aged twenty-eight, was admitted into the Sheffield Pablic Hospital and Dispensary, under my care, on the 31st of January last, suffering from paraplegia. He had noticed some weakness in his legs since shortly after Christmas, but had experienced no difficulty in walking until about a week before he was admitted. He had had some pain about the upper lumbar vertebræ, and at first slight twitchings in both lower extremities, beginning in the right. The usual inquiries into his previous history elicited the following facts: He had had good health until he was between twelve and fourteen years of age, when he had a sore on his tongue, a hard swelling beneath the jaw, and a sore throat and mouth. He could not remember having any rash or spots on his skin, but said hat his hair came off in considerable quantity soon after the appearance of these symptoms. Neither he nor his father could give a satisfac. tory account of the order in which they occurred. The sore on the tongue took three or four months to heal. Later he had a discharge from the nostrils, and the bridge of his nose sank in. He said that he was again under medical treatment for an affection of both eyes, when he was about sixteen or eighteen years of age. In 1876 be was a patient in the hospital with paraplegia involving the sphincters, but recovered almost completely in the course of a year. He then had fairly good health up to the commencement of his present illness. Inquiries into his family history elicited nothing beyond the fact that of ten brothers and sisters only two were living; of the other eight several were stillborn, and several fell victims to an epidemic of small-pox. His father was living and well, aged seventy, and his mother died of "dropsy" at the age of forty-seven. 'I'he patient had been married seven years, and his wife had had one miscarriage, and one child living and well. $\mathrm{He}$ was fairly well-nourished, but had a very sallow, earthr complexion, and a very flattened, syphilitic-looking nose. On the dorsum of his tongue, to the right of the median line, was a depressed and puckered cicatrix. The soft palate was partially destroyed by old ulceration, and adherent on the right side to the back of the pharynx. There were no scars about the body, face, or limbs, no swelling or nodes, no scar on the penis, and no history of venereal disease could be obtained. He complained on admission of slight pain in the back, referred to the upper lumbar vertebræ, and some tenderness on percussion over the spinous processes in the same situation. He experienced a feeling of some stiffness, but no pain in bending or rotating the spine. In the horizontal position with great muscular effort, be could just raise his heel half an inch from the bed, but could not retain it in that position. Both lower extremities were affected equally. There was no wasting and no rigidity or contraction in the muscles of the paralysed limbs, their electro-contractility to faradaism being slightly increased. Cutaneous sensibility was normal below the knee, but lost over the outer surface of both thighs, corresponding to the distribution of the external cutaneous nerve. Over the abdomen, back, buttocks, and posterior and inner surface of both thighs sensation was normal. The superficial reflexes were increased, except the cremasteric reflex, which was absent on both sides. Patellar-tendon reflex was exaggerated in both limbs, and ankle clonus was very marked in the right leg, only slightly noticeable in the left. There was a small patch of interstitial opacity on the left cornea, and with the ophthalmoscope slight cloudiness of the right cornea was detected. The discs were healthy, but there was a slight crescent-shaped patch of choroidal atrophy to the outer side of the right disc. The pupils were normal, and there were no traces of former iritis. The heart, lunge, urine, temperature, and pulse afforded no indication of any abnol. mality. The tongue was clean and moist, and appetite good, but the patient complained of abdominal pain, and had very troublesome diarrhoea. The liver and spleen were not enlarged. Under iodide of potassium, increased from ten. up to twenty-grain doses, and mercurial inunction over the spine, the patient made rapid progress towards recovery day by day. On the sixteenth day after admission he was able to walk a little without as:istance, and soon after left the hos- 
pital at his own request. On March lst, when I last saw him, he walked easily, only dragging the right foot slightly, and told me that he had walked four miles the day before. Sensation over the outer surface of both thighs was nearly normal, but the cremasteric reflex could not be obtained; ankle clonus could still be elicited in the right leg, but was not so marked.

I think there can be no doubt of the syphilitic character of the lesion in this case, though the source of the poison is not satisfactorily accounted for by the history. We have no positive evidence of venereal infection; there is no scar on the penis, and in this matter we have no reason to doubt the man's word that he never had any disease there. The first symptoms mentioned are the sore on the tongue and ulceration of the palate, but as to which occurred first neither the patient nor his father can enlighten us. Indeed, from the uncertainty displayed by the patient as to the order and date of the earlier symptoms, I am inclined to place so little reliance on his accuracy that I am far from convinced that the eye affections were not among the earlier phenomena, the case one of congenital syphilis, and the sore on the tongue a gummatous ulcer. There is a striking absence of those symptoms of nerve irritation and compression which characterise the earlier stage of the progress of tumours originating externally to the cord itself. There were no neuralgic pains, hyperæsthesia, \&c. There was some slight pain referred to the upper lumbar vertebræ, and some sensitiveness to pressure in this situation; but the patient was able to bend and rotate the vertebral column freely and without complaint. There was none of the stiffness and acute pain on rotating the spine, with rigidity of the spinal muscles, which we find in tumours affecting the meninges and in spinal meningitis. The only premonitory symptoms alluded to by the patient were muscular twitchings, and these he did not lay any great stress upon, and they do not appear to have been very marked. They were speedily followed by paralysis of both lower extremities, the right slightly preceding the left. The symptoms point, I think, to an affection of the cord sub stance itself, the anterior or motor portion being primarily and principally involved. There was no rapid wasting or loss of electro-contractility in the paralysed muscles to indicate an affection of the motor nuclei in the anterior cornua of the grey matter; but the symptoms were rather those of a lesion spreading horizontally through the anterior and lateral columns and cutting off the communication, at some point, between the brain and the lower portion of the cord. The power of the will over the portion of the cord from which the lower lumbar and sacral nerves are derived was almost completely lost; and both cutaneous and muscular reflexes showed an increased response to stimulation on the part of this portion of the cord, proving that the control normally exercised by the higher centres was intercepted at some point higher up. On testing the cutaneous sensibility there was found to be a patch of anæsthesia on the outer surface of each thigh corresponding to the distribution of the external cutaneous nerve, a branch of the second lumbar. There was no loss of sensation over the surface supplied by the ilio-hypogastric or ilio-inguinal nerves, branches of the first lumbar; nor was there any anæsthesia corresponding to the distribution of the middle and internal cutaneous branches of the anterior crural, which comes from the third and fourth lumbar nerves. The only cutaneous reflex which was wanting was the cremasteric reflex, or the drawing up of the testicle by the cremaster muscle in response to stimulation of the surface supplied by the ilio-inguinal nerve on the upper and inner aspect of the thigh. I have just said that there was no loss of sensation in the skin, which derives its supply from this nerve, therefore it was not the sensory impulse which was wanting; but the cremaster muscle receives its motor supply from the genito-crural, the other branch of the second lumbar nerve. From these facts it would seem that the lesion in the cord must have been situated about the point of origin of the second lumbar nerve, principally, if not entirely, in the anterior and lateral columns of both sides, and that by pressure upon the posterior roots of that nerve the loss of sensation in the skin supplied by the external cutaneous might be accounted for. The presence of patellar-tendon reflex and ankle clonus negatives any affection travelling down the posterior columns; and the phenomenon, observed mostly on the right side, I take it, indicates probably some secondary descending lesion in the lateral columns.

Syphilis attacking the cord itself, from the few cases recorded, appears to have a preference in the first instance for the anterior or motor portion. In non-syphilitic neoplasms, on the other hand, the tendency appears to be to involve primarily the central grey matter of the cord. Speaking of these syphilitic lesions, Lancereaux says that they generally leave intact, in part at least, the sensibility, and, above all, the reflex movements of the extremities; and that while complete paraplegia accompanied by painfal sensations in the course of the nerves, and by contraction of the muscles, indicates more particularly a lesion of the coverings of the cord, on the other hand, complete paraplegia with reflex movements is rather the sign of a primary lesion of the cord itself.

Sheffield.

\section{ON THE NATURE AND TREATMENT OF SEA-SICKNESS.}

By T. T. REYNOLDS, M.D., SURGEON, STEAMSHIP " CITY OF CHICAGO."

THE altered sensory impressions affecting those at sea interfere with the coördination of movements by which the body is adapted to its surroundings, and with the vomiting and other centres in the medulla oblongata. This interference causes sea-sickness. The coördination of movements depends principally on the action of the corpora quadrigemina, the cerebellum, and the medulla oblongata, affected by the ordinary sensory impressions, and also by what Foster calls " the afferent impulses, as it were, of a new sense" from the semicircular canals, arising from variations of pressure in their ampullæe. The pitching and rolling of a ship must cause the pressure on the ampulle to vary greatly, and thus interfere with the ordinary afferent impulses by which the body is balanced. Consciousness can influence the coördinating mechanism, and set right the confused condition caused by the disturbed sensory impressions. This corrective power of the conscious ego may be acquired or strengthened by experience, as is seen every day among sailors and passengers. In cases where the internal ear has been injured by otorrhoea following scarlatina or measles, we may suppose that the person learns to balance himself without the intervention of this new sense, the absence of which is compensated for in some way; and it is a curious fact, and one which throws considerable light on the etiology of sea-sickness, that such persons invariably escape this disease. Twelve such cases of deaf people I have met with in which the deafness was traceable to otorrhoea. That deafness in itself does not prevent seasickness is in keeping with the fact that the afferent impulses from the semicircular canals do not give rise to auditory sensations. 1 The cases of those persons who become sea-sick from sleeping on board a ship the night before sailing, when she is lying in dock, resemble the hysterical simulation of other diseases.

These views on sea-sickness, though written three years ago, are much the same as those held by Dr. Irwin, and published by him in THE LANCET of Nov. 25th, 1881, but they differ in some important points. While he believes a structural change, "irritative hyperæmia" of the semicircular canals, to be the cause of sea-sickness, there are reasons to believe no such change exists. If the disturbed motions of the endo-lymph produced a condition of irritative hyperæmia, we should expect this condition to become more marked the longer the motions continued, and also that all sailors and persons exposed to these motions would suffer from this structural change and its consequent sea-sickness. These conditions are not fulfilled, and so we are forced to believe that the altered sensoly impressiors of those at sea affect the medulla directly, independent of any structura change in the semicircular canals; and that sea-sickness is prevented by their action being mollified, or nullified, by the educated conscious ego.

With regard to the symptoms of sea-sickness, I only mention those which bear on its etiology and treatment. The first is excessive glandular action, the salivary glands. being those soonest affected. Efferent impulses from the secretion centre in the medulla descend by the chorda tympani and excite this salivary secretion. Now we know that atropine paralyses the secretion centre in the 